\title{
Importance and Challenges of Green Supply Chain Management in Healthcare
}

\author{
Ahmed W., Asim M., and Manzoor S.
}

\begin{abstract}
This research is related to the importance of the Green Supply Chain Management within in Healthcare sector. Further, the challenges related to it are also discussed. Green building operations are necessary not only for the population but for the environment as well. Awareness related to it is increasing especially in the area of the supply chain management areas. Efficient Supply chain management is necessary within the healthcare sector. Social \& economic benefits are generated through green supply chain management. Supply chain management plays a significant role in waste management. Communication \& government challenges are considered to be some of the challenges of the Green Supply Chain Management within in Healthcare sector.

Keywords - Information Technology; Green Supply Chain Management; Healthcare Management
\end{abstract}

\section{INTRODUCTION}

Nowadays the concern for pollution is at its peaks and this is due to constant industrialization [10]. It is a big threat to human health and also harms future generations to come. For this reason, firms and customers are moving towards eco-friendly products which is our last chance for the world to become a sustainable place for us. Customers demand high-quality products from production lines. This case also implies on construction industries from constructing to demolishing [8] [5]. The beauty of the building is not just the main requirement over here but efficient allocating of resources is also important. This includes that materials that are eco-friendly and are recyclable are encouraged to reduce additional cost and for the sake of a sustainable future. Civil engineers and constructers are required to be 'green' in the structuring stage.

The whole supply chain has to follow this procedure including suppliers, subcontractors. All participants of the supply chain have to look for a green supply chain [7]. A sustainable system has been adopted by GSCM to aid in waste management. In this group, both country Turkey and the European Union have given regulations on proper construction and demolishing techniques [9]. There are to objectives they follow for raw materials. Either they should reduce the quantity or recover minimum resources as possible. For green buildings resources such as water and energy can be saved as part of the initial process [5]. Further elaboration on the details will be given in another subheading for certification of green building.

There are a lot of things that are considered before conducting the study [12] [5]. Many different aspects have to be given great attention and many of them need to work in a proper manner to be implemented. It can be seen that the need for effective green implementation in the supply chain is necessary. Though, there might be many things that

Published on March 11, 2020. may harm this aspect and needs to be looked upon carefully [5]. These aspects that result in the hindrance in green management, must be known and then effectively removed. The main issue that arises here is about finances and overall technological improvements [12]. The need for the green supply chain has increased and that is why the research needs to see the problems in it and effective solutions must be identified. The future requires organizations to be green, and that is what this is all about.

The main reason why the study is being conducted is to make sure that the challenges in the green supply chain management are discovered [3]. Specifically, the challenges in the healthcare sector. This is important to know because this identifies a significant aspect of the need for the green supply chain management. The purpose of the study is to therefore, find any challenges in green supply chain management and to work on their improvement for the best results [4]. There are many challenges related to this as well. Therefore, this needs to be identified as well.

The research question is related to identifying the problems that are related to green supply chain management for healthcare organizations. There are significant challenges in green healthcare supply chain management and they need to be understood.

\section{LITERATURE REVIEW}

Green building operations is crucial to the people and the environment. The environmental awareness aspect can be seen to grow every year and, especially in the supply chain management aspect, this has its effect on major aspects and different sectors. These sectors are the hospitals and healthcare in general. According to Ahi, and Searcy (2013) both talked about Green supply chain and general green management, going towards a greener working environment [1]. This is the main aim here as development, diffusion, use construction of green buildings, etc. are all common aspects in the green environment that we work in. in order to have a green supply chain, one must first manage their organizations to be green as well. According to Diabat, and Govindan (2011) both of them agreed that the world health organization has stated some key elements that need to be followed in this case [4] [9].

It can be said that these aspects need to be implemented in the supply chain management aspect as well. The first thing that has been stated is related to applying efficiency measures and reducing energy consumptions and the overall cost. According to Sarkis, Zhu, and Lai, (2011), they stated that this is an important aspect to be implemented in the works of green supply chain management [12]. Another important aspect that was talked about was related to building in order to reduce the resources that are consumed 
and also to keep the environment into consideration. According to Green (2012), he said that there are other things stated as well related to the supply chain which includes, proper disposal of the materials that have been used throughout the supply chain. There are a lot of aspects to consider in green supply chain management and all of them have their significance and have to be accomplished to fulfil the process.

There are certain waste management aspects that need to be used. The green supply chain management helps in reducing the raw materials firstly that have been brought in. the differentiation needs to be made in the materials needed and the strength [9] [10]. According to Muduli, and Barve (2013) they agreed that there are different material types that are available and thus this difference is hard to understand [10] [11]. Therefore, the conclusion that has been stated is that using greener materials in the structures and then making them strong, is an impossible task. Therefore, there have been new materials that are used as substitutes. According to Sarkis, Zhu, and Lai, (2011), they stated that they are light, and also durable [12]. Furthermore, these are also recyclable and that is a link to green supply chain management. The waste materials would be used in the other construction projects and they would be used as second quality materials this can be done if there is an effective closed loop. If the regulation goal needs to be achieved then the waste amount is to be reduced which is recovered at the lifecycle end. The green hospitals would lead to a reduction of the materials and will also give energy savings. The green hospital is known to take the initiative of becoming environmentally friendly through supply chain management and use building materials that are green.

It is important to see that green supply chain management will result in social and economic benefits while also agreeing on the requirements of the government. Supply chain management in waste management is important. According to Ahi, and Searcy (2013) both talked about A closed-loop supply chain would be important [1]. The disposal of waste material needs to be reduced. This GSCM includes the recycling repairing and the remanufacturing of the aspects. The materials recovered would then be sold and would benefit. The GSCM in the green hospital would result in many benefits. With the help of GSCM, the raw materials are mostly recyclable and are used less. This aspect can be established with the efficiency of the GSCM the beginning and the end of the chain is shown, the lifecycle is known to keep the people and the environment safe.

There are a lot of ways in which green work can be done through green supply chain management. The concept of reverse logistics is used to assist the delivery of the products in an efficient manner and flow in a straight one direction. According to Muduli, and Barve (2013) they agreed that the reverse logistics aspect can be implemented in the redistribution of the materials [13]. This can be spread throughout the supply chain. There are certain activities that are included as reverse logistics. This includes the modifications, packaging, returns processing, salvation, remanufacturing, landfill and recycling. The main focus of reverse logistics is related to retrieving the used products from the consumption point to the origin. According to Chang et al (2019), they talked about This shows the product transformation and the aspects that can be reused [2] [5]. Then the other aspect is related to the return that is done, or the relevant takeback that is done from the consumption point to forward it for the supply chain for recycling, remanufacturing, cleaning, reuse and disposing of it safely.

The concept of reverse logistics is implemented as integrating supply chain management into the environmental thinking process [8] [13]. When the concept of greening the supply chain management is talked about, it can be seen that this seeks to balance the issues of the environment with the marketing performance. This includes the finance flow, integration flow, information flow, environment management, synergy between partners, promoting efficiency, cost savings, facilitates environment performance and minimal waste. Remanufacturing includes collecting the used products and the components from the field, which then replaces the worn, look at the situation, then replace the broken parts and refurbish the parts. Here, the original function that the product had is now preserved [12] [7] [9]. To recycle is to collect the used products and then separate then and set them into the categories of the materials. Then they are processed where the original function is lost.

This aspect cannot be ignored when talking about green Supply Chain Management. It is important to notice that there is a lot of challenges that healthcare organizations face when implementing the concept of green Supply Chain Management [4] [13]. It is absolutely critical to identify the needs of the farming society and learn about the changing future. As time passes, the need to invest in more greener ways is increasing. It is necessary o now the importance of green Supply Chain Management because this aspect faces a lot of challenges the most basic supply chain management challenge is related to how there is a lack of care in this matter. [7] As talked about before, there is a need to work for green Supply Chain Management. If in the future, success is needed, then the ways need to be changed. According to Diabat, and Govindan (2011) both of them agreed that organisations need to care about the environment and they need to care about the people in order to work in a way that benefits them and the environment that is around the society [4] [5]. The lack of care is causing most of the problems. If the organizations are ready to go green, their suppliers are not ready. They work for money and they believe that the cost of going green would increase. This is a major downfall and a major disadvantage that is faced in this manner. If there is no care for going green, then there won't be any success in the future. People look for companies that care for them and their environment. If the customers see that a company is going against their ethical beliefs, then they would boycott that company [7] [9]. This can very well happen with healthcare organizations as well. People might change their organizations because they might find it harder to adjust in the constantly changing environment and the inconsistency that the organizations have.

Another important challenge that is faced when implementing green Supply Chain Management in the health care industry is related to finance. According to Green (2012), he said that there are many organizations out there that need to go green. These organizations want to 
work in a sustainable manner and work for the environment. Though going green is expensive and changing everything could be very critical for the finances of a certain organization. Money becomes an important issue and needs to be countered. When money comes in question, this results in massive downfall in the need to go green. The organization is hell-bent on staying alive in the market. Therefore, only big organizations have the necessary funds to do the task.

Another task that is faced when implementing the green Supply Chain Management process is related to communication. Though this aspect is not new, it is still quite unfamiliar with the people. Green Supply Chain Management is a universal aspect, but it has not been implemented to such an extent. According to Ahi, and Searcy (2013) both talked about there is often a lack of information and often this leads to a lack of communication [1] [9]. With this breakdown in communication, it is important to understand that there might be many different problems that might arise. These problems are linked to the Green Supply Chain Management aspect. Therefore, proper communication needs to be done as some people might understand it but others may not. The way of doing things changes and it takes time to assess the things that have been stated.

Then comes another challenge. This challenge is related to the government. The government is the main player here. If the government wants, then they could make every company work in a green manner. According to Green (2012), he said that though, instead of doing anything, they have simply implemented laws that apply the need to go green. Though, they have not done anything important that actually leads to going green. They have not subsidized smaller organizations to use finance in investing in a greener working environment [3]. The biggest player is the government and things might go well if they decide on fixing these things rather than implementing and leaving laws to be followed.

Perhaps one of the major problems/challenges that are faced is related to the inner strength of the organization. In many cases, it can be seen that an organization is not strong from the inside when focusing on the aspect of green supply chain management [7]. According to Sarkis, Zhu, and Lai, (2011) they stated that for instance, a human resource department needs to be strong enough to make their workers understand the change [13]. The department needs to be strong enough to handle the suppliers and their aspects. The overall weakness of the organization results in great losses to the company in the form of reputation. If the human resource management system is efficient, then they would be able to effectively establish a green supply chain management system.

This is defined as a purchasing activity that is environmentally conscious. This makes sure that the materials and the products that have been purchased, meet the goals of the environment that have been set. This is also called, an environmentally conscious purchasing that focuses on the firm's environmental objectives [6]. This also has its main focus on the elimination of hazardous goods. They also include aspects such as using fewer resources and wasting less, etc. The measurement for this is done on the basis of product content requirements, product content labelling or disclosure, certification providers, EMSs, compliance audit of the supplier, questionnaire on suppliers and product content restrictions.

This aspect is defined as the implementation of the environmental issues that have the activities which consist of packaging that is green, the logistics and the proper green transport. The distribution is affected highly by the packaging [12] [9]. This includes the shape, the size and the materials that affect the distribution as the transport characteristic is affected. When there are better packing and the order patterns are improved, then the material consumption is reduced to a great extent. Then the green distribution is also done with reducing warehouse space and the amount for handling requirements should also be reduced.

This is the plant's ability to produce in a greater efficient manner then deliver the products to the customers in an effective manner. The Operational Performance (OP) can be measured by the reliability, inventory and production alternate cycle time [8] [7]. The supply chain management here needs to be improved and considerable focus needs to be given here. It can be said that, if an organization is not properly equipped to deal with greener matters, then they would have troubles in green supply chain management.

\section{Methodology}

The research that was present is related to the type of work done and the questions that were asked. The research was related to asking about the green supply chain management and whether it is implemented here or not. It is important to understand the depth of the research. A set of 15 questions were placed and through selective management, there were participants selected and then the relevant research was conducted. The data collection was done through the process of using google forums. This was done so that there would be ease of conducting the survey and that there would not be any significant issues with the questions. The data was then collected and then arranged in an excel file when they were filled out. This type of research is a qualitative research that is conducted. It is about the questionnaires that have been placed. When the results had been collected, they were then placed in the SPSS version 24. Through this, the graphs and the results had been placed in one place to further look upon the results of the research.

The population size was selected based on a series of important decisions. These participants had to fulfil certain age criteria and qualification criteria that needed to be met. The population size that had been taken for the research was 30. 30 participants were chosen to be a part of this research and give out their answers to the questions that had been asked, as per the qualitative research method.

The sampling technique is related to the random sampling method. Although, the participants were required to clear a specific criterion, out of those the random sampling took place. This random sampling method that had been done was because this brought in ease for the participants. They were emailed randomly and then required to participate.

When research is conducted, it is the job of the researcher to keep in mind the ethical rights that are available. These ethical rights are a way to make sure that there are no 
problems related to the participants. It was made sure that the participants had agreed upon a relevant structure of research. The participants were told about the research and their complete consent was taken before they were included in their research. The participants' information had also been kept a secret as this is an important thing to consider. Their privacy was protected through the research and a strong confidentiality level was kept [13]. The complete information about the research was given and nothing was left out that might have impacted their decision on doing the research. Furthermore, it was made sure that there was no misleading information given to the participants. Everything in the research was kept strictly professional.

\section{ANALYSIS}

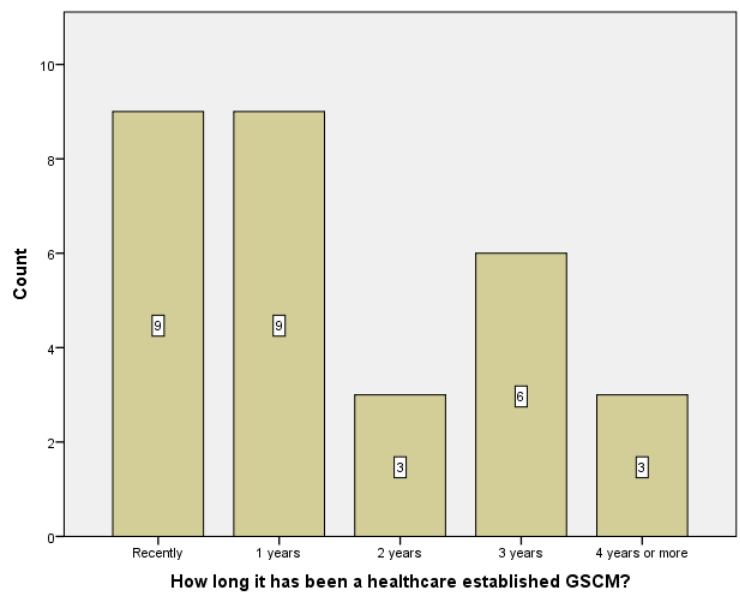

At the initial point, it has boomed and shown great results as being the most top response around 9 counts which is highest recently which means this practice is very much acceptable and this can be seen in the first year as well where the count remains constant at 9 showing a bit of consistency in the graph. As it is the question of the sustainable green program recently it is very much adaptable and people are moving towards green building, however, in the other hand it has declined to 3 and then fluctuated to 6 and in the final year, 3 again showing that throughout the trend is not much adopted.

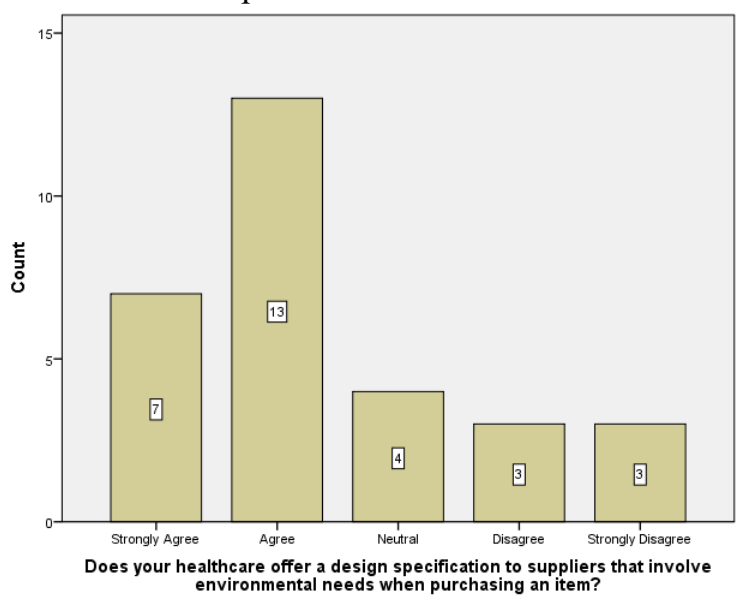

The question is asked whether the customers or society demand specific designing for suppliers to follow when manufacturing a product. The graph shows how much people agree to the question. Near to half people agree to the question as it is 7 of people who strongly agree that this initiative should be taken. While 13 just agree, that also means people are conscious of their consumption pattern. On the other hand, 4 are neutral about their decision which means they have not made up their minds yet. 3 people disagree and strongly disagree as well which means this kind of people judge their product quantitatively rather than qualitatively which in future is not a healthy practice.

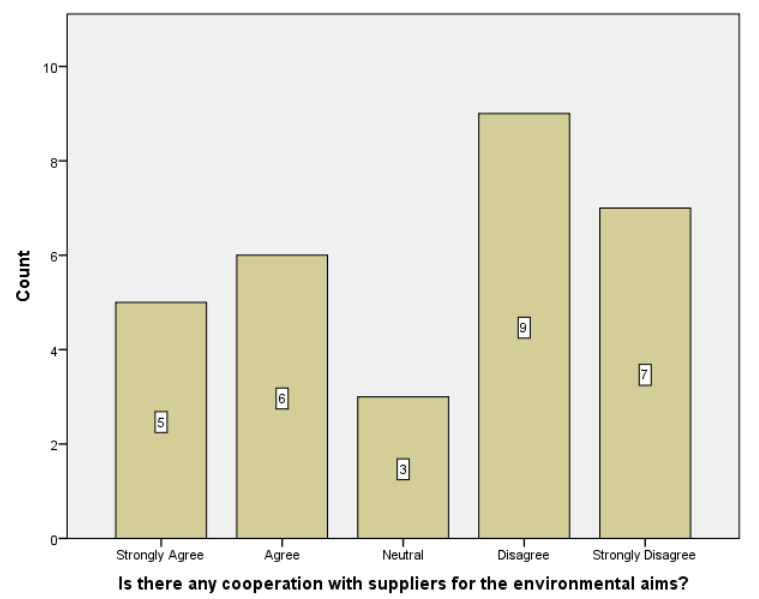

There seems to be a cooperation with the suppliers as 5 have strongly agreed on this matter, 6 have agreed as to their answer. While it can also be seen that 3 have been neutral in this case while 9 have disagreed. This was followed by 7 who have also strongly disagreed. It can be seen that there is a lack of supplier involvement in this aspect.

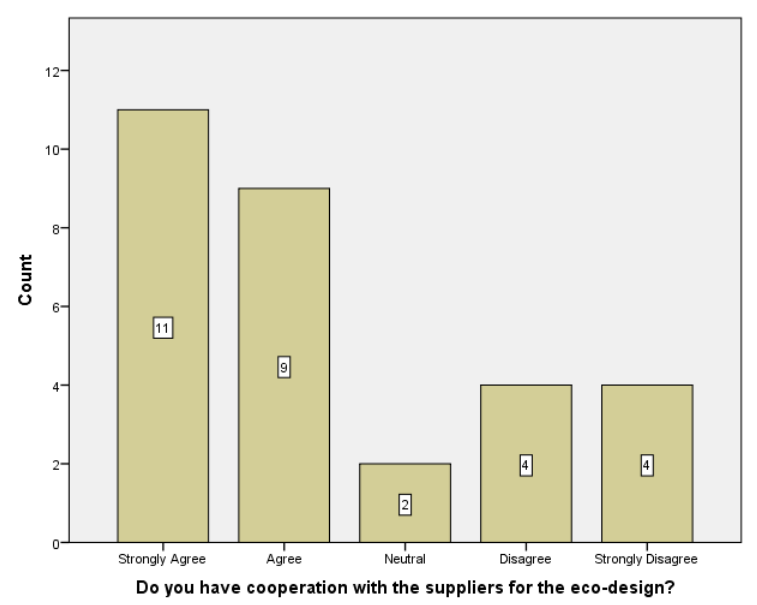

This question is about that is there any cooperation between us and the suppliers to provide eco-friendly products. The graph shows that 11 strongly agree as it is reasonable to cut cost down like this. 9 agree which shows that going green is a suitable choice as it reduces cost and reuse of materials. 2 are neutral as they are not sure that whether this process will be beneficial or not for them. 4 people disagree and strongly disagree respectively. As they might not see any benefit in this process or they may be not informed of the benefits or lack of knowledge about it. 


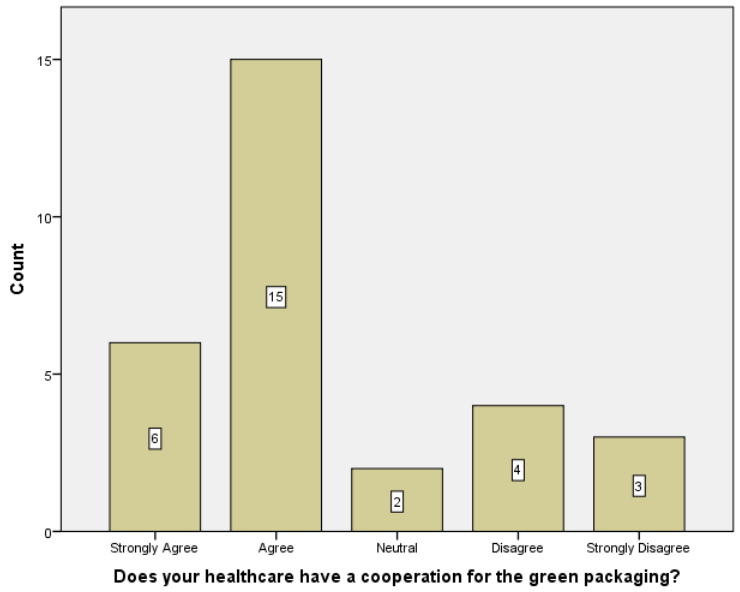

This question emphasis green packaging. Though suppliers are being careful about manufacturing but are they using the green system in packaging as well. 6 strongly agree as they are concerned about waste pollution such as packaging can cause, 15 agree to it which is the highest response showing that people care about green packaging and avoid packaging's like plastics. 2 people are neutral about the idea as they might not have any opinion about the idea. 4 and 3 disagree and strongly disagree respectively. Showing that people may have no interest once they consume their product and have no responsibility for waste disposal.

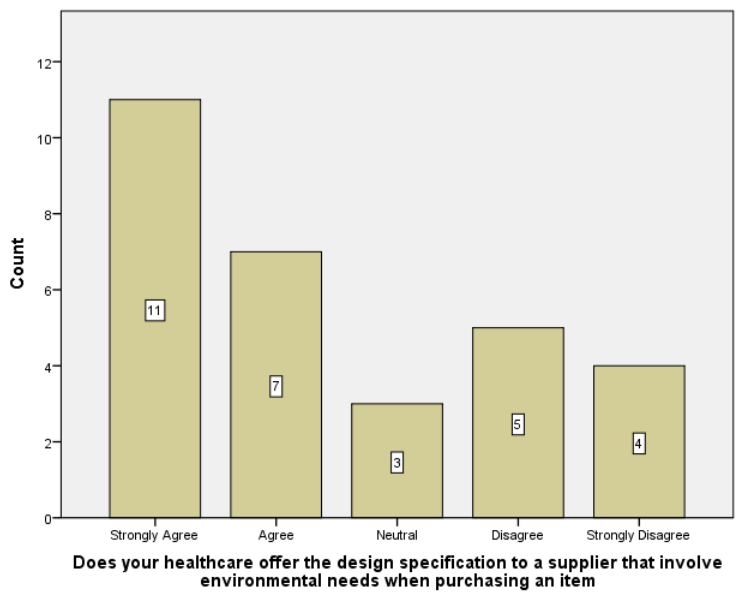

With this question, there are 11 participants who have strongly agreed on this matter of design specifications. 7 have also agreed on this matter and 3 have stayed neutral. While there were 5 who disagreed and 4 that strongly disagreed. It can be seen that design specifications have been provided yet they need to be simply implemented as well.

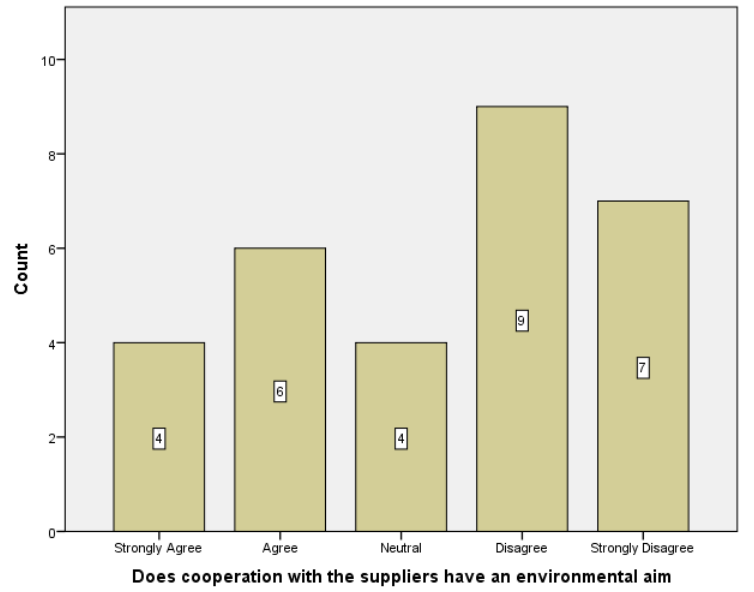

With this question, 4 have strongly agreed and 6 have agreed. There are 9 participants that have disagreed and 7 that have strongly disagreed on the matter. What more needs to be seen here is that fewer participants have talked about any environmental aim with their suppliers. The fact is that the need for change must be present to work on implementation.

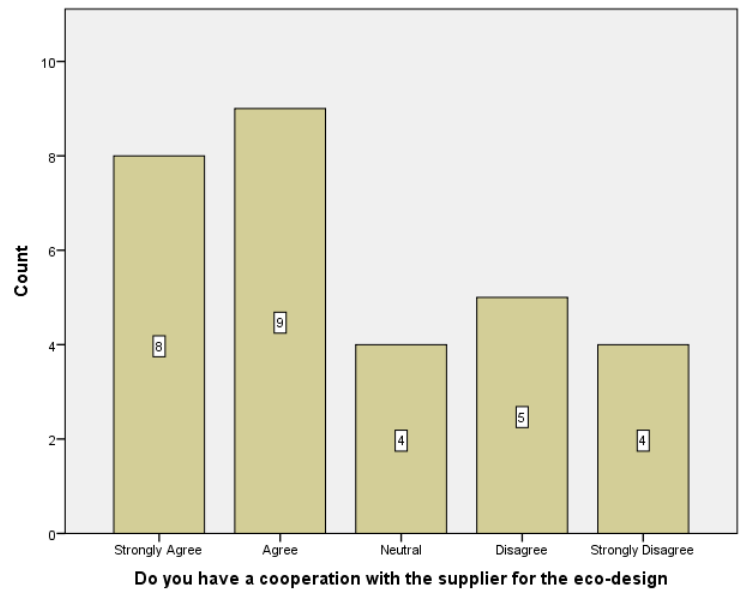

Here, 8 have strongly agreed on the matter, 9 have agreed, 4 have neutral aspects, 5 have disagreed and 4 have strongly disagreed. Keeping the strongly disagreed in mind, it can be said that this number is less. It seems that some sort of cooperation is available as the numbers for agreeing are higher.

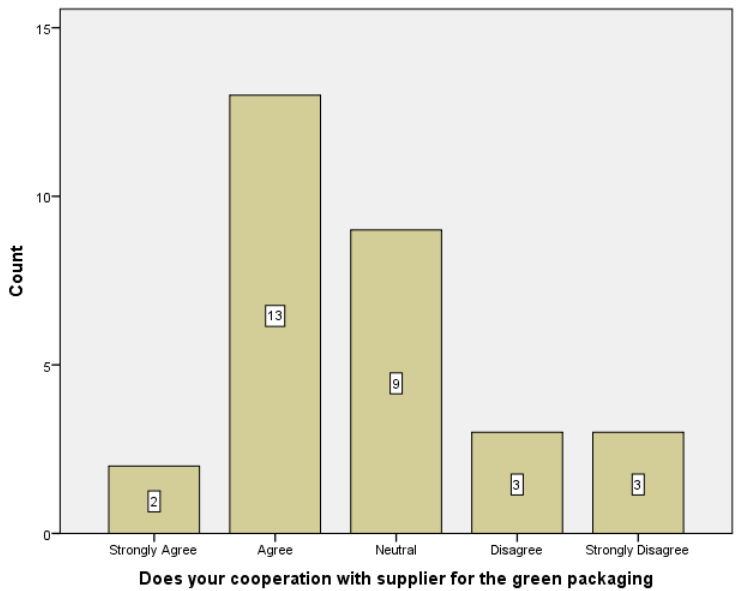

The participants were asked about the cooperation with the suppliers about the green packaging. Out of the 30 participants, there were quite a few answers. Only 2 people 
strongly agreed about this cooperation. There were considerable agreements, around 13, related to this. 9 people had neural thoughts about this. There were further 3 people who had disagreed from this viewpoint. And then there were 3 people who had strongly disagreed about this cooperation this shows that suppliers do want to work in a green manner and that is why they need to be pushed about the deal and the work that is done. If there is cooperation, then it would be easier for the work to be done in an effective manner.

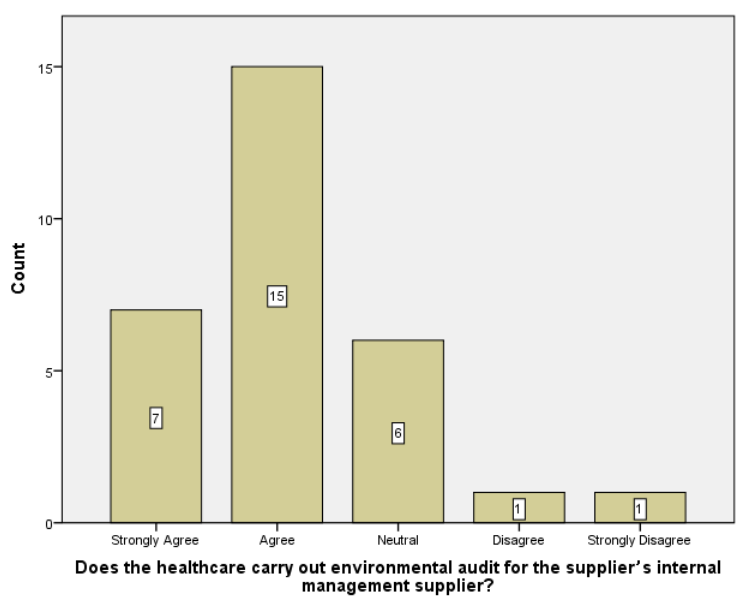

Another question was asked about the healthcare and if the healthcare does the environmental audit for the management of the suppliers. The question is relevant in this case as it talks about health care and their interest in working in a green manner. There were 7 people who had strongly agreed to the case as this means that with this the environmental audit is necessary. Even 5 participants agreed to the fact that an environmental audit was pushed for and seeing as 6 people were neutral, it became an important task to accomplish. Furthermore, only the remaining participants disagreed and strongly disagreed. Therefore, the conclusion over here is that green supply chain management is a necessary aspect and is welcomed by the healthcare system.

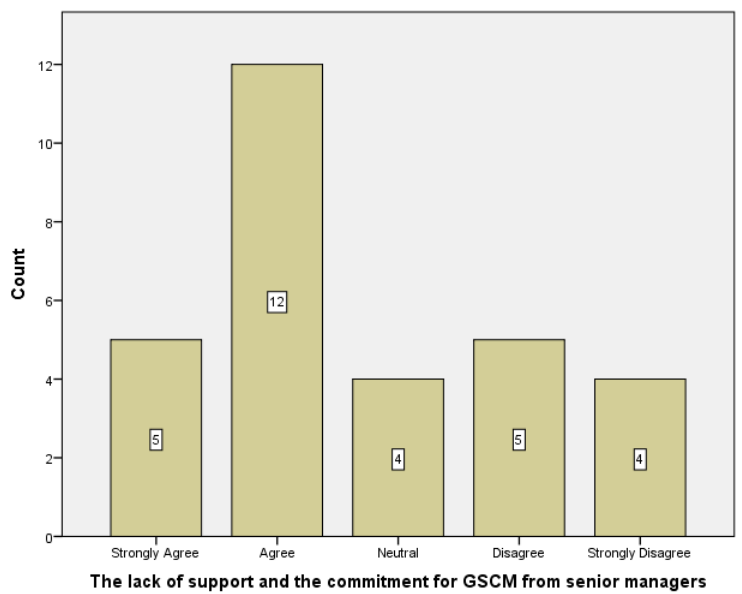

Then the participants were asked about the support for the GSCM and how the senior managers were not paying enough attention to it. 5 participants agreed about the fact that there was a lack of support. This was backed up by 12 more participants. Though 4 were neutral in this case. There were participants who also disagreed with this case as the number was 5 and then there were 4 participants who strongly disagreed. Therefore, here it is safe to say that there is support for GSCM. The participants who disagreed and strongly disagreed, it is safe to say that they engage in GSCM in an effective manner. Though, it can be seen that people need to have a greater idea about the GSCM and need to be pushed in its direction.

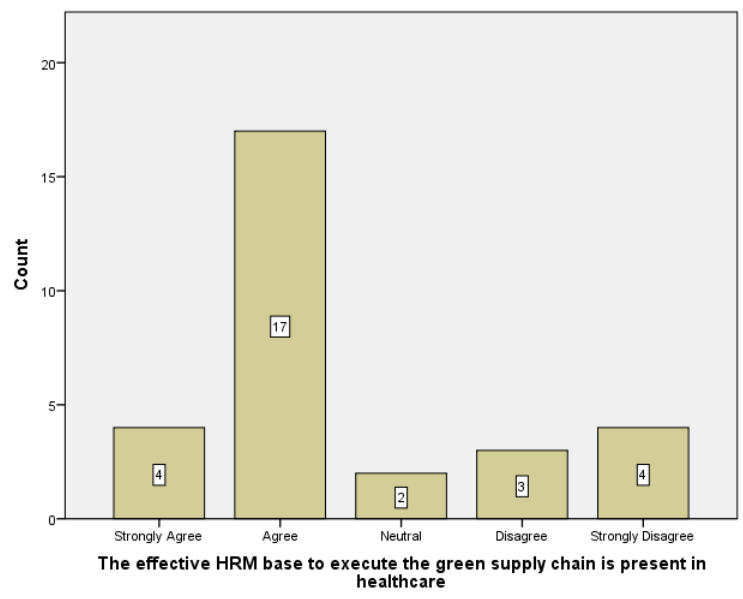

Then an important question about how human resources are ready to deal with the green supply chain in healthcare was asked. This is an important question as it shows how strong organizations are from the inside in dealing with this matter.4 participants strongly agreed in this matter as they believed that the human resources in their organizations were equipped strongly. 17 participants also agreed in this matter which shows the organizations' desire to work in a green manner. 2 participants had neutral thoughts and 3 disagreed about this aspect. 4 participants though, had strong disagreements about the situation. Henceforth, this shows that most HRM is ready to implement green supply chain in health care.

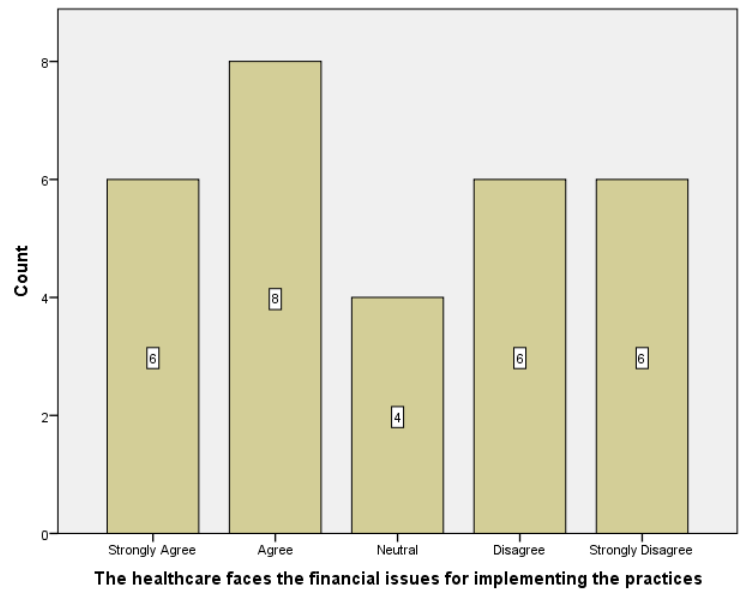

Then another important question was asked by the researcher. The researcher asked about the financial constraints related to these green practices. There were 6 participants that strongly agreed on this matter. Then others agreed here as well, 8 participants to be exact. These participants agreed on the fact that there were financial constraints that limited the healthcare's ability to work in a green manner. 4 participants replied as neutral and 6 of then disagreed on the fact. It could be said that these organizations were well equipped for the future. The same can be said for the remaining 6 who also strongly agreed. 


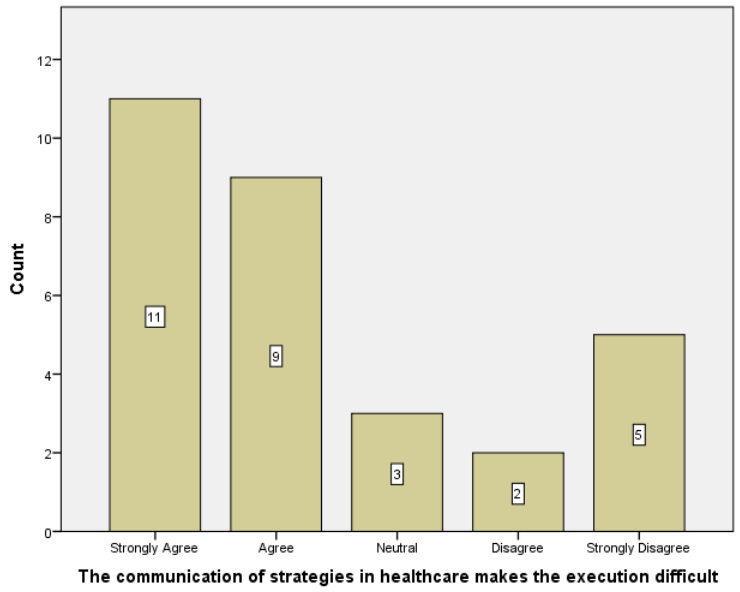

In this question, a few technical aspects come to play. It can be seen that there are considerable problems in the communication of the strategies that are used in healthcare. This affects the execution to a great extent. There were 11 participants who strongly agreed on the fact that communication was not effective and that is what led to the major issues in the system. 9 other participants also agreed on this fact as they too believed that there were some problems with the communication. 3 participants found this to be quite neutral and 2 of them disagreed on this fact as well. 5 of them strongly disagreed in this manner and it can be assumed that their communication was strong as this was an important thing for them.

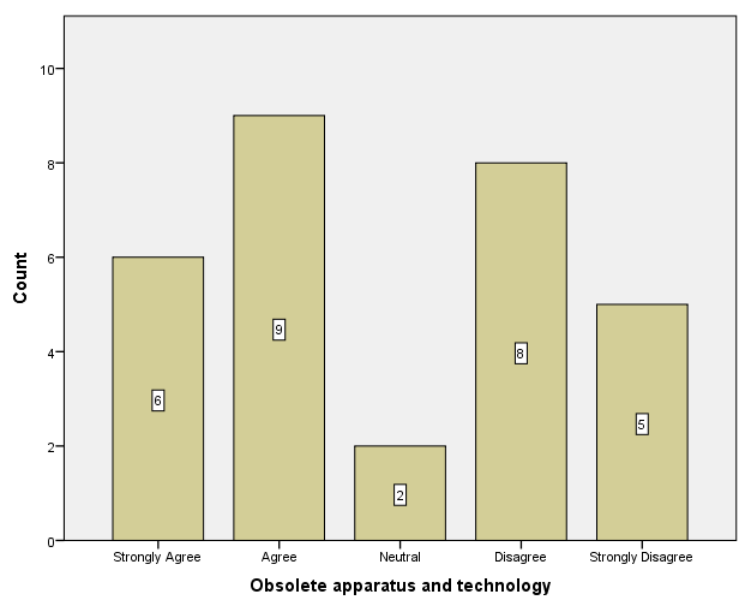

There are a lot of things that may harm the work and lead to problems. The existence of obsolete technology and apparatus found out to be a relevant question. With this, there were 6 participants who strongly agreed on the fact that proper technology was not available to reach the goals of the organization. Then, 9 other participants agreed on this matter as well. The remaining had different perspectives as 8 disagreed on this matter and 5 also did the same. Though the question here is about the reason this issue is being faced. There are healthcare organizations that need to work in an effective way. It is necessary to see that there is a lack of technology available to implement this change. If there are organizations, then they find these problems. This, together with financial issues, makes it harder to implement GSCM.

\section{CONCLUSION}

In the end, the complete research has been conducted about the need for green supply chain management in health care. There were many relevant aspects that have been identified and many things that further need to be identified. Though the problems exist, such as cooperation, finance, technological advancements, it is important to understand that, this is not just the issue. There are a lot of different issues which are identified and more need to be identified. There is a lot more room for research a lot of improvements need to take place in green supply chain management. The participants selected and the research conducted, all of them proved to be valuable. The final verdict out of all of this was related to the fact that there are people that want to work in a green manner, but have great restrictions that need to be removed. Further, there are also people who are working in a green manner as they have been doing it for quite some time. All of this proves that green supply chain management, especially in healthcare, is the way to go.

There is room for a lot of research as there can be many improvements done. For the future, it can be seen that many different participants can be selected for the task. It can be said that there are a lot of things to be found here. For instance, the number of participants was limited to just 30 . This number needs to be increased and more people need to be brought in the research. It can also be seen that room for improvement is also available with the sampling method for accurate data, specialized people need to be selected with the most specific sampling method.

\section{REFERENCES}

[1] Ahi, P. and Searcy, C., "A comparative literature analysis of definitions for green and sustainable supply chain management" Journal of cleaner production, 52, pp.329-341, year 2013.

[2] Chang, H.C., Wang, M.C., Liao, H.C. and Wang, Y.H., "The Application of GSCM in Eliminating Healthcare Waste: Hospital EDC as an Example" International journal of environmental research and public health, 16(21), p.4087, year 2019.

[3] De Vries, J. and Huijsman, R., "Supply chain management in health services: an overview" Supply Chain Management: An International Journal, 16(3), pp.159-165., year 2011.

[4] Diabat, A. and Govindan, K., "An analysis of the drivers affecting the implementation of green supply chain management" Resources, Conservation and Recycling, 55(6), pp.659-667, year 2011.

[5] Fahimnia, B., Sarkis, J. and Davarzani, H., "Green supply chain management: A review and bibliometric analysis" International Journal of Production Economics, 162, pp.101-114, year 2015.

[6] Green Jr, K.W., Zelbst, P.J., Meacham, J. and Bhadauria, V.S., "Green supply chain management practices: impact on performance" Supply Chain Management: An International Journal, 17(3), pp.290305, year 2012.

[7] Jacobs, F.R., Chase, R.B. and Lummus, R.R., "Operations and supply chain management" (Vol. 567). New York: McGraw-Hill Irwin, year 2011.

[8] Lee, S.M., Lee, D. and Schniederjans, M.J., "Supply chain innovation and organizational performance in the healthcare industry" International Journal of Operations \& Production Management, 31(11), pp.1193-1214, year 2011.

[9] Lin, R.J., "Using fuzzy DEMATEL to evaluate the green supply chain management practices" Journal of Cleaner Production, 40, pp.32-39, year 2013 .

[10] Muduli, K. and Barve, A., "Barriers to green practices in health care waste sector: an indian perspective" International Journal of Environmental Science and Development, 3(4), p.393, year 2012.

[11] Muduli, K. and Barve, A., "Sustainable development practices in mining sector: a GSCM approach" International Journal of Environment and Sustainable Development, 12(3), pp.222-243, year 2013. 
[12] Sarkis, J., "A boundaries and flows perspective of green supply chain management" Supply chain management: an international journal, 17(2), pp.202-216, year 2012.

[13] Sarkis, J., Zhu, Q. and Lai, K.H., "An organizational theoretic review of green supply chain management literature" International Journal of Production Economics, 130(1), pp.1-15, year 2011.

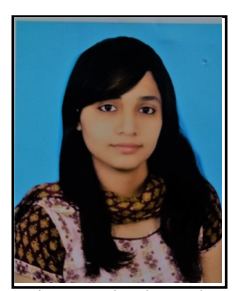

Miss Wajeeha Ahmed born in Karachi on June 1994, Bio medical and supply chain expert contributing in connecting both fields

She has done her MBA in Supply chain management from Karachi University Business School, 2020. Before that she completed her $\mathrm{BE}$ in Bio medical from NED University

Miss Wajeeha Ahmed working as Assistant Project Manager at Information Technology Services in Karachi. Previously completed her internship in Dow medical. 